\title{
Changes in paediatric respiratory infections at a UK teaching hospital 2016-2021; impact of the SARS-CoV-2 pandemic
}

\author{
Sheila F. Lumley ${ }^{\mathrm{a}, \mathrm{b}, *}$, Nicholas Richens ${ }^{\mathrm{a}}$, Emily Lees ${ }^{\mathrm{c}}$, Jack Cregan ${ }^{\mathrm{b}}$, Elizabeth Kalimeris ${ }^{\mathrm{a}}$, \\ Sarah Oakley a, Marcus Morgan ${ }^{a}$, Shelley Segal ${ }^{a}$, Moya Dawson ${ }^{a}$, A. Sarah Walker ${ }^{b, d, e}$, \\ David W. Eyre ${ }^{\mathrm{a}, \mathrm{d}, \mathrm{e}, \mathrm{f}, \mathrm{g}}$, Derrick W. Crook ${ }^{\mathrm{a}, \mathrm{b}, \mathrm{d}, \mathrm{e}}$, Sally Beer ${ }^{\mathrm{a}}$, Alex Novak ${ }^{\mathrm{a}}$, \\ Nicole E. Stoesser ${ }^{\mathrm{a}, \mathrm{b}, \mathrm{d}, \mathrm{e}, 1}$, Philippa C. Matthews ${ }^{\mathrm{a}, \mathrm{b}, \mathrm{d}, \mathrm{e}, 1, *}$
}

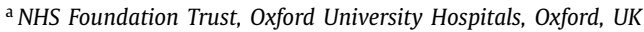

${ }^{\mathrm{b}}$ Nuffield Department of Medicine, University of Oxford, Medawar Building, South Parks Road, Oxford OX1 3SY, UK

${ }^{c}$ Department of Paediatrics, University of Oxford, Oxford UK

${ }^{\mathrm{d}}$ NIHR Oxford Biomedical Research Centre, University of Oxford, Oxford, UK

e NIHR Health Protection Research Unit in Healthcare Associated Infections and Antimicrobial Resistance, University of Oxford, Oxford, UK

${ }^{\mathrm{f}}$ Nuffield Department of Population Health, University of Oxford, Oxford, UK

${ }^{g}$ Big Data Institute, University of Oxford, Oxford, UK

\section{A R T I C L E I N F O}

\section{Article history:}

Accepted 26 October 2021

Available online 29 October 2021

\section{Keywords:}

Respiratory virus

Respiratory tract infection

Paediatric

SARS-CoV-2

Respiratory syncytial virus

Influenza

Rhinovirus

\section{S U M M A R Y}

Objective To describe the impact of the SARS-CoV-2 pandemic on the incidence of paediatric viral respiratory tract infection in Oxfordshire, UK.

Methods Data on paediatric Emergency Department (ED) attendances (0-15 years inclusive), respiratory virus testing, vital signs and mortality at Oxford University Hospitals were summarised using descriptive statistics.

Results Between 1-March-2016 and 30-July-2021, 155,056 ED attendances occurred and 7,195 respiratory virus PCRs were performed. Detection of all pathogens was suppressed during the first national lockdown. Rhinovirus and adenovirus rates increased when schools reopened September-December 2020, then fell, before rising in March-May 2021. The usual winter RSV peak did not occur in 2020/21, with an interseasonal rise (32/1,000 attendances in 0-3 yr olds) in July 2021. Influenza remained suppressed throughout. A higher paediatric early warning score (PEWS) was seen for attendees with adenovirus during the pandemic compared to pre-pandemic ( $p=0.04$, Mann-Witney $U$ test), no other differences in PEWS were seen.

Conclusions SARS-CoV-2 caused major changes in the incidence of paediatric respiratory viral infection in Oxfordshire, with implications for clinical service demand, testing strategies, timing of palivizumab RSV prophylaxis, and highlighting the need to understand which public health interventions are most effective for preventing respiratory virus infections.

(C) 2021 The Authors. Published by Elsevier Ltd on behalf of The British Infection Association. This is an open access article under the CC BY license (http://creativecommons.org/licenses/by/4.0/)

\section{Introduction}

Respiratory tract infections (RTI) represent a major global disease burden in children, particularly in children under five years of age. Lower RTI are one of the top ten causes of mortality and

* Corresponding authors at: Nuffield Department of Medicine, University of Oxford, Medawar Building, South Parks Road, Oxford OX1 3SY, UK.

E-mail addresses: sheila.lumley@trinity.ox.ac.uk (S.F. Lumley), philippa.mathews@ndm.ox.ac.uk (P.C. Matthews).

1 These authors contributed equally to this work morbidity considered by the World Health Organisation (WHO). ${ }^{1}$ Although many RTIs are mild and self-limiting, they remain one of the commonest reasons for primary care consultation, attendance in emergency departments, hospital admission and antibiotic prescribing. In the UK, incidence of upper RTI is around 300,000 cases per 100,000 people per year, ${ }^{2}$ with children $<5$ years experiencing as many as 10 infections/year. ${ }^{3}$

Prior to the SARS-CoV-2 pandemic, common causes of RTI included bacterial pathogens (e.g. Streptococcus pneumoniae [in settings with low vaccination rates], Haemophilus influenzae) and viruses such as respiratory syncytial virus (RSV), influenza, 
Table 1

Paediatric respiratory virus testing policies during study period.

\begin{tabular}{|c|c|c|}
\hline Date & Test* & Policy \\
\hline March & \multirow[t]{2}{*}{ Flu A/B/RSV PCR } & Only test if changes clinical management. \\
\hline 2016 & & All suspected febrile neutropenia during Flu/RSV season \\
\hline- & \multirow[t]{3}{*}{ Biofire multiplex respiratory PCR } & Admission to ITU/HDU with a respiratory illness. \\
\hline Jan & & Suspected febrile neutropenia - if URTI symptoms \\
\hline 2020 & & OR at clinician's discretion \\
\hline Feb & SARS-CoV-2 PCR & Child requiring admission for at least one night AND clinical evidence of pneumonia/pneumonitis \\
\hline 2020 & \multirow[t]{2}{*}{ Flu A/B/RSV PCR } & Only test if changes clinical management. \\
\hline- & & All suspected febrile neutropenia during Flu/RSV season \\
\hline June & \multirow[t]{2}{*}{ Biofire multiplex respiratory PCR } & Admission to ITU/HDU with a respiratory illness \\
\hline 2021 & & OR at clinician's discretion \\
\hline July & \multirow[t]{3}{*}{ Biofire multiplex respiratory PCR } & Admission to ITU/HDU with a respiratory illness \\
\hline 2021 & & OR requiring an aerosol generating procedure \\
\hline & & OR at clinician's discretion \\
\hline & Flu A/B/RSV \& SARS-CoV-2 PCR & All other children requiring admission \\
\hline
\end{tabular}

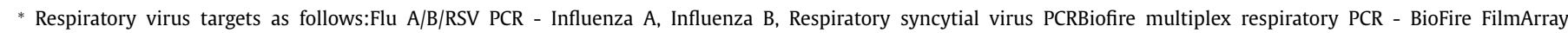

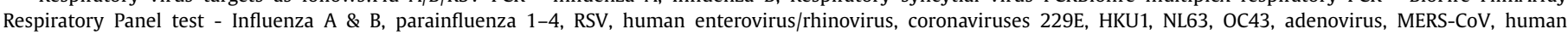
metapneumovirus (SARS-CoV-2 included from October 2020 as part of the BioFire FilmArray Respiratory Panel test 2.1).

parainfluenza, adenoviruses, rhinovirus, respiratory enteroviruses and non-SARS-CoV-2 human coronaviruses (hCov), with viral infections accounting for $\sim 40-50 \%$ of RTI presentations. Symptomatic paediatric SARS-CoV-2 infection remains uncommon, accounting for $<2 \%$ of COVID-19 cases in England, with few severe infections and deaths $(1-5 / 100,000$ paediatric infections requiring admission, and even fewer requiring intensive care admission). Particular attention has been related to rare presentations in children with paediatric multisystem inflammatory syndrome temporally-associated with SARS-CoV-2 (PIMS-TS) which can be life-threatening, with $44 \%$ of PIMS-TS admissions in the UK requiring intensive care. ${ }^{4-6}$

Notably however, the SARS-CoV-2 pandemic has resulted in major observed changes to the wider epidemiology of RTIs, driven by social distancing, use of face coverings and periods of lockdown including closure of daycare and educational settings. This has led to reduced opportunities for virus transmission, and potential shifts in interactions and competition amongst respiratory pathogens. This includes significant reductions in non-SARS-CoV2-associated RTIs in adult and paediatric populations. ${ }^{7-13}$ Atypical rebounds and peaks in rhinovirus and RSV infections have been observed following the loosening of social restrictions and reopening of educational settings, likely partly driven by waning population immunity given the lack of exposure to these pathogens during $2020 .^{14-23}$ This has been particularly prominent in the case of RSV, with presentations reported in a significantly older population of children than would usually be affected. ${ }^{23}$

Here, we describe the impact of the COVID-19 pandemic on the incidence of paediatric viral RTI in Oxfordshire, UK.

\section{Materials and methods}

Oxford University Hospitals (OUH) is a tertiary referral centre consisting of four hospital sites in Oxfordshire: three hospitals in Oxford serving a population of 655,000 , and a fourth in Banbury with a catchment population of around 150,000. Emergency Departments (ED) in Oxford and Banbury see children between the age of 0 and 15 years.

Data on paediatric ED attendances, baseline characteristics such as age, gender, ethnicity, index of multiple deprivation (IMD), hospital admission (general wards vs. critical care), respiratory virus test results (within the first $24 \mathrm{~h}$ after arrival at ED), vital signs (all heart rate, respiratory rate and oxygen saturation readings recorded in the ED) and mortality (within 14 days of a positive respiratory virus test) were sourced from the Infections in Oxfordshire Research Database (IORD, https://oxfordbrc.nihr.ac.uk/research- themes-overview/antimicrobial-resistance-and-modernisingmicrobiology/infections-in-oxfordshire-research-database-iord/).

During the study period, respiratory virus testing was performed according to local protocols, detailed in Table 1. Platforms used are detailed in supplementary Table 1.

Data on the strictness of lockdown policies restricting people's behaviour in England were sourced from Oxford COVID-19 Government Response Tracker (OxCGRT). ${ }^{24}$ This 'stringency index' is calculated from containment and closure policy indicators capturing information on containment and closure policies such as school closures and restrictions in movement, plus an indicator recording public information campaigns.

Data were categorised into pre-pandemic (before 23-Mar-20) and pandemic (23-Mar-20 onwards) periods. 23-Mar-20 was the date that the UK government announced plans for a national lockdown, selected here to reflect the approximate time when widespread behaviour changes occurred in the UK, rather than the date when SARS-CoV-2 was first introduced into the UK. As only heart rate, respiratory rate and oxygen saturations were reliably available, partial Paediatric Early Warning Scores (PEWS) using the Alder Hey PEWS, ${ }^{25}$ were used as a marker of disease severity, and calculated based on highest heart rate, highest respiratory rate and lowest oxygen saturation recorded, in attendances where all 3 parameters were available.

\section{Statistical analysis}

Data analysis was performed using $R$ version 4.0.2. For comparisons between pre-pandemic and pandemic periods, Pearson's Chi-squared test was used for categorical data and Mann-Whitney $U$ test for numeric data. Kruskal-Wallis was used for comparisons between the PEWS for different pathogens.

\section{Ethical approvals}

IORD has generic Research Ethics Committee, Health Research Authority and Confidentiality Advisory Group approvals (REC Ref 19/SC/0403; ECC5-017(A)/2009).

\section{Results}

Demographics of patients presenting to paediatric ED

Between 1-March-2016 and 30-July-2021, 155,056 paediatric ED attendances were recorded from 81,339 individuals (supplementary Fig. 1). The median number of attendances per individual 
Table 2

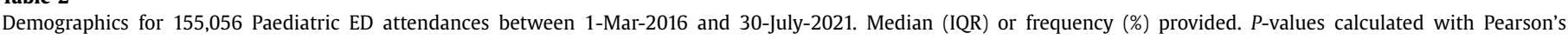
Chi-squared test for categorical data and Mann-Whitney $U$ test for numeric data.

\begin{tabular}{|c|c|c|c|c|}
\hline & \multirow{2}{*}{$\begin{array}{l}\text { Overall } \\
(n=155,056)\end{array}$} & \multicolumn{2}{|l|}{ Time period } & \multirow{2}{*}{$\begin{array}{l}P \text {-value (comparing pre-pandemic } \\
\text { vs. pandemic time periods) }\end{array}$} \\
\hline & & $\begin{array}{l}\text { Pre-pandemic } \\
(n=124,390)\end{array}$ & $\begin{array}{l}\text { Pandemic } \\
(n=30,666)\end{array}$ & \\
\hline \multicolumn{5}{|l|}{ Age group in years } \\
\hline $0-3 ;$ pre-school & $64,096(41.3 \%)$ & $51,619(41.5 \%)$ & $12,477(40.7 \%)$ & \multirow[t]{3}{*}{0.0001} \\
\hline $4-11 ;$ primary school & $58,734(37.9 \%)$ & $47,182(37.9 \%)$ & $11,552(37.7 \%)$ & \\
\hline 12-15; secondary school & $32,226(20.7 \%)$ & $25,589(20.6 \%)$ & $6637(21.6 \%)$ & \\
\hline \multicolumn{5}{|l|}{ Sex } \\
\hline Male & $87,010(56.1 \%)$ & $69,821(56.1 \%)$ & $17,189(56.1 \%)$ & \multirow[t]{3}{*}{0.76} \\
\hline Female & $68,044(43.9 \%)$ & $54,567(43.9 \%)$ & $13,477(43.9 \%)$ & \\
\hline Not stated & $2(<0.1 \%)$ & $2(<0.1 \%)$ & 0 & \\
\hline \multicolumn{5}{|l|}{ Ethnicity } \\
\hline White & $118,314(76.3 \%)$ & $94,619(76.1 \%)$ & $23,695(77.3 \%)$ & \multirow[t]{7}{*}{$<0.0001$} \\
\hline Asian & $10,005(6.5 \%)$ & $8146(6.5 \%)$ & $1859(6.1 \%)$ & \\
\hline Mixed & $7537(4.9 \%)$ & $5957(4.8 \%)$ & $1580(5.2 \%)$ & \\
\hline Black & $3250(2.1 \%)$ & $2694(2.2 \%)$ & $556(1.8 \%)$ & \\
\hline Chinese & $1029(0.7 \%)$ & $875(0.7 \%)$ & $154(0.5 \%)$ & \\
\hline Other & $2876(1.9 \%)$ & $2196(1.8 \%)$ & $680(2.2 \%)$ & \\
\hline Not Stated & $12,045(7.8 \%)$ & $9903(8.0 \%)$ & $2142(7.0 \%)$ & \\
\hline IMD Score & $11.7(7.1-20.1)$ & $11.7(7.1-20.4)$ & $11.4(7.1-19.9)$ & 0.0002 \\
\hline Monthly attendance frequency & $2492(2080-2693)$ & $\begin{array}{l}2580(2390- \\
2729)\end{array}$ & $1871(1538-2148)$ & 0.0002 \\
\hline $\begin{array}{l}\text { Monthly admission rate (per } 1000 \\
\text { attendances) }\end{array}$ & $208(193-222)$ & $211(200-220)$ & $186(175-230)$ & 0.02 \\
\hline $\begin{array}{l}\text { Monthly critical care admissions rate (per } \\
1000 \text { attendances) }\end{array}$ & $7(4-9)$ & $8(6-9)$ & $2(1-4)$ & $<0.0001$ \\
\hline $\begin{array}{l}\text { Paediatric early warning score (PEWS) for } \\
\text { positive cases }\end{array}$ & $1(0-2)$ & $2(0-2)$ & $1(0-2)$ & 0.24 \\
\hline $\begin{array}{l}\text { Deaths within } 14 \text { days of a positive PCR (per } \\
100 \text { positive PCRs) }\end{array}$ & 0.6 & 0.8 & 0.3 & $<0.0001$ \\
\hline
\end{tabular}

"Pre-pandemic" is defined as prior to 23-Mar-2020, "Pandemic" is defined as 23-Mar-2020 onwards. IMD = index of multiple deprivation.

$\mathrm{PCR}=$ polymerase chain reaction.

was 1 (IQR $1-2$, range $1-52$ ). $41.3 \%$ were aged $0-3$ years, $37.9 \%$ aged $4-11$ and $20.7 \%$ aged $12-15$. The majority of attendances were by males $(87,010(56.1 \%))$ and children of white ethnicity $(118,314$ (76.3\%)). The median Index of Multiple Deprivation score (IMD) was 11.7 (IQR 7.1-20.1, range 0.5-80; a lower score indicates less deprived areas, placing the median score in the 2nd least deprived quintile in England). There were small but statistically significant differences in age, ethnicity and IMD score between pre-pandemic and pandemic periods (Table 2 ).

Pre-pandemic, a median of 2580 attendances were recorded per month, with peaks in attendance each November in the $0-3$ year age group. A median of 211 cases (8.2\% of attendances) were admitted per month, $8(0.3 \%)$ to critical care. During the pandemic, median attendance was lower at 1871 per month $(p=0.0002)$, and the usual seasonal winter peaks were lost, with an atypical summer peak in attendance in June/July 2021 (> 1250 attendances per month, compared to usual June/July attendance rates of $\sim 900 /$ month). A median of 186 cases were admitted per month (10\% of attendances), $2(0.1 \%)$ to critical care $(p=0.02$ and $p<0.0001$ compared to pre-pandemic, respectively) (Table 2 , Fig. 1A).

\section{Respiratory virus testing patterns over time}

A total of 7195 respiratory virus tests were performed on children during the period observed (1179 FluA/B/RSV PCR, 1005 Biofire respiratory multiplex PCR and 5011 SARS-CoV-2 PCR). Respiratory virus testing rates varied by assay and time (Fig. 1B). A median of 4.5 Influenza A/B/RSV PCRs/1000 attendances were performed pre-pandemic, compared to 7.2/1000 attendances during the pandemic $(p=0.95)$, a median of 3.9 Biofire multiplex PCR/1000 attendances were performed pre-pandemic, com- pared to $16.7 / 1000$ attendances during the pandemic $(p<0.0001)$. No SARS-CoV-2 PCRs were performed pre-pandemic, compared to $163 / 1000$ attendances during the pandemic. Demographic differences between those tested vs. not tested are shown in supplementary Table 2 .

Prior to the pandemic the majority of tests $(1119 / 1355 ; 83 \%)$ were performed on $0-3$ year olds, $182 / 1355$ (13\%) on $4-11$ year olds and $54 / 1355$ (4\%) on $12-15$ year olds. During the pandemic testing increased in the older age groups; $3039 / 5840$ (49\%) of tests were performed on $0-3$ year olds, $1773 / 5840$ (30\%) on $4-11$ year olds and $1028 / 5840(18 \%)$ on $12-15$ year olds, reflecting changes in attendance patterns and testing policies over time.

\section{Respiratory virus detection rates over time}

One or more respiratory viruses was identified on 1128/7195 (16\%) respiratory virus tests, on 935/155,056 ED attendances. The distribution of viruses in pre-pandemic and pandemic periods are shown in Fig. 2 and Supplementary Table 3. Rates of pathogen detection varied over the study period and by assay performed (Fig. 1C). The first case of paediatric SARS-CoV-2 in this study was seen on 24-Mar-20, and in the period since the start of the pandemic it has accounted for $15 \%$ of respiratory viruses diagnosed in patients attending Paediatric ED.

Pre-pandemic, seasonal peaks of RSV and influenza A/B were observed in September-February and December-March, respectively, and to a lesser extent with hCoV in December-March. Rhinovirus and adenovirus exhibited less seasonal variation, with rising case numbers in February in some years. Numbers of parainfluenza and metapneumovirus were too low to detect seasonal variation. The highest incidence of diagnoses was seen in the 0 3 year olds for all pathogens (Fig. 3). 

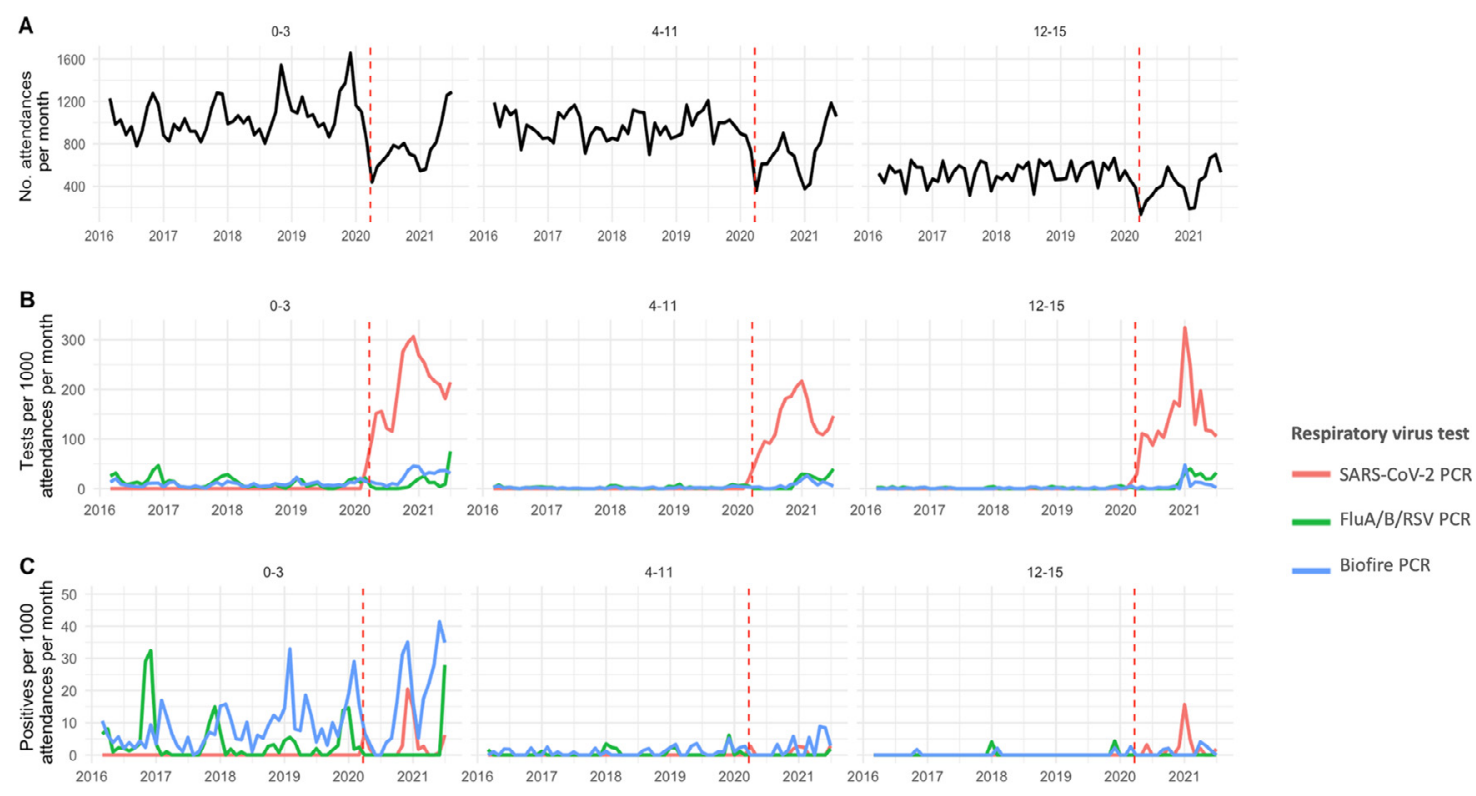

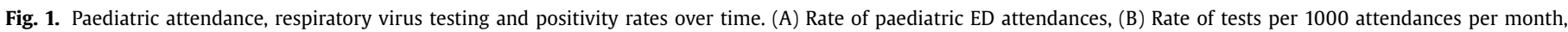
(C) Rate of positives per 1000 attendances per month. Left hand panels show 0-3 years, central panels 4-11 years and right hand panels 12-15 years.

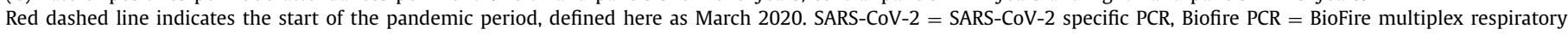
PCR.

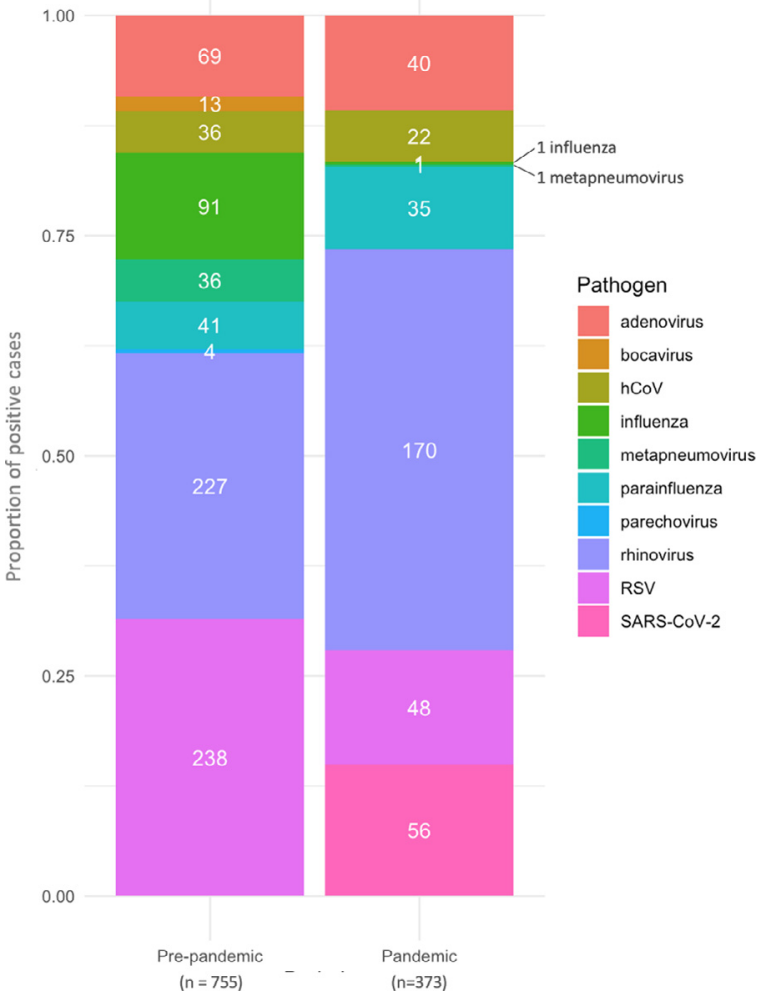

Fig. 2. Respiratory virus detection in children age $0-15$ pre- and during the SARSCoV-2 pandemic. Stacked bars represent proportions of pathogens during each period. Frequency of individual pathogens are shown in white text, with totals for each period in the $\mathrm{x}$-axis legend. Respiratory viruses were detected using (i) Influenza A/B/RSV PCR, (ii) Biofire respiratory multiplex PCR, (iii) SARS-CoV-2 PCR or (iv) Cepheid Flu A/B/RSV/SARS-CoV-2 (see supplementary Table 1).

The patterns of suppression and resurgence during the pandemic varied by pathogen (Figs. 3, Supplementary 2). Detection of all pathogens was suppressed during the first national lockdown and during summer 2020 ( 7 months). Rhinovirus
(Fig. 3B) and adenovirus (Fig. 3D) were the first pathogens to re emerge in September 2020 with incidence rising to 25 and 10 cases/1000 attendances/month in the 0-3 year age group, respectively (a period where schools and childcare facilities were open and lockdown rules were relaxed). Rates fell in January-February 2021, during a period of increased stringency of lockdown measures, then rose again March-June 2021 to 19 and 6 cases/1000 attendances/month in the 0-3 year age group, respectively, when stringency of lockdown measures was reduced. No statistically significant difference was seen in age of attendees between pandemic vs pre-pandemic periods (rhinovirus: pre-pandemic $0.7 \mathrm{yr}$ [IQR 0.3-1.6] vs. pandemic $1.3 \mathrm{yr}[0.7-2.1], p=0.46$ and adenovirus: pre-pandemic $1.2 \mathrm{yr}$ [0.6-1.6] vs. pandemic $1.3 \mathrm{yr}$ [1.1-1.8], $p=0.35$, Chi-squared).

In contrast, RSV (Fig. 3A) cases remained suppressed for the first 15 months of the pandemic, much longer than rhinovirus and adenovirus; the usual seasonal winter peak did not occur in 2020/21. In July 2021 RSV rates rose out of season in the pre-school age group (32/1000 attendances/month in 0-3 yr olds), more than double the rate seen pre-pandemic in December 2019 (14/1000 attendances/month). The median age of RSV attendees was higher during the pandemic (pre-pandemic $0.3 \mathrm{yr}$ [IQR 0.2-0.9] vs. pandemic 1.8 yr [IQR 0.7-2.8], $p=0.03$, Chi-squared).

Influenza $\mathrm{A} / \mathrm{B}$ (Fig. $3 \mathrm{C}$ ) remained suppressed throughout the pandemic period reported here, with only 1 sample positive in October 2020. This was from a two year old child, with both Influenza A and B detected by PCR, which is highly likely to represent detection of vaccine strain following recent intranasal seasonal influenza vaccination (Fluenz Tetra, which contains live attenuated influenza $\mathrm{A}$ and $\mathrm{B}$ ). Parainfluenzavirus and hCoV rates were unusually high in May-June 2021 to 12 and 7 cases/1000 attendances/month in the $0-3$ year age group, respectively (Fig. 3F,G). Very few cases of metapneumovirus (Fig. 3E) were seen during the pandemic, however baseline rates are usually low.

\section{Samples positive for multiple respiratory viral pathogens}

Of the 935 ED attendances where a positive respiratory virus test was obtained, 770 tested positive for one pathogen and 165 for 

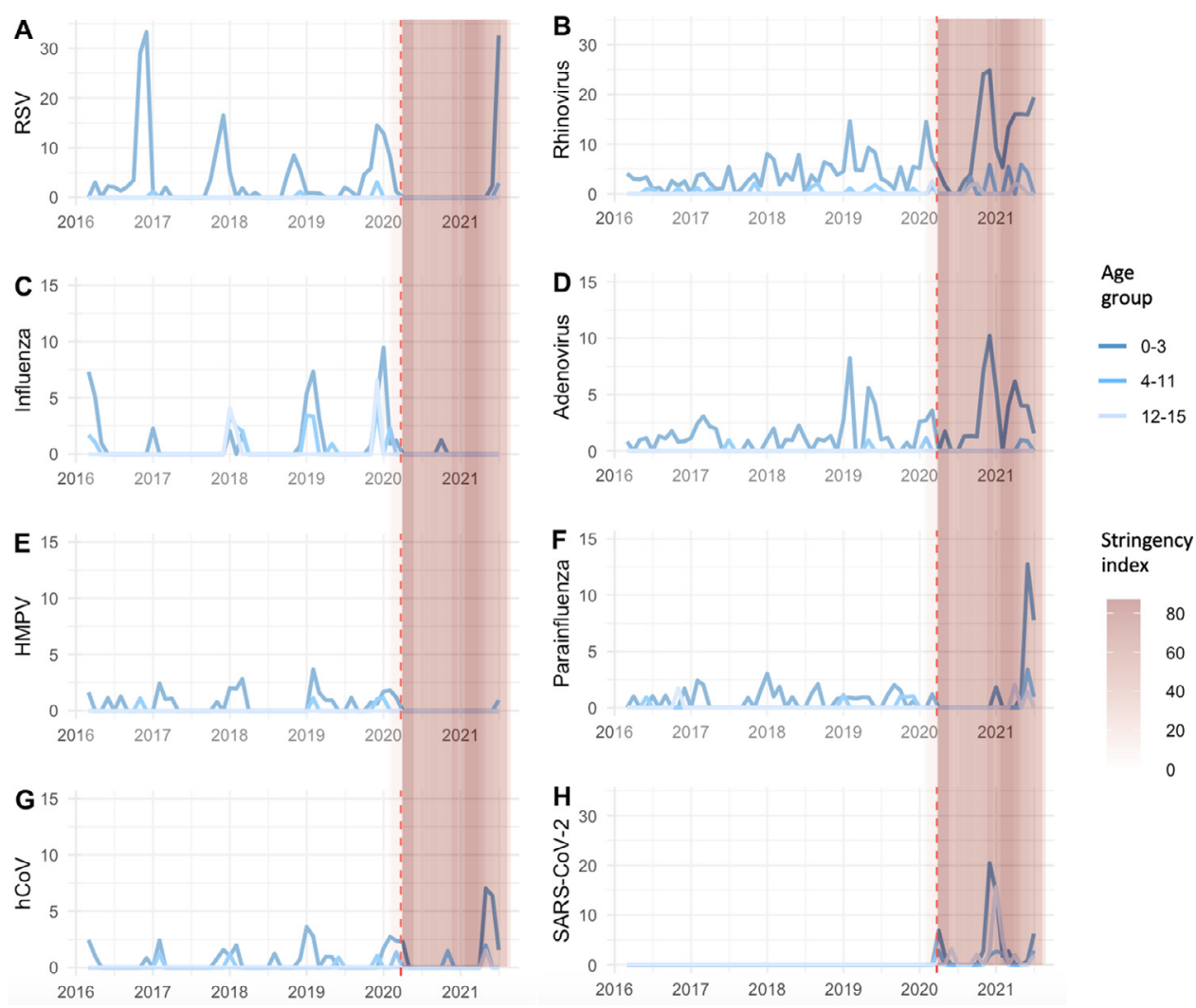

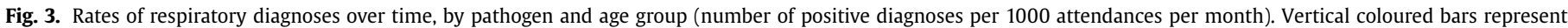

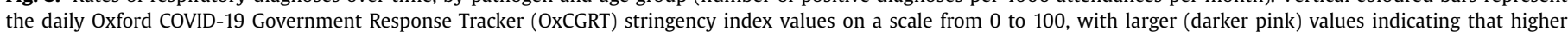

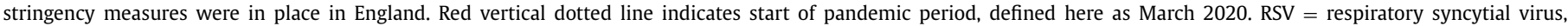
$\mathrm{HMPV}=$ human metapneumovirus, hCoV = human coronaviruses (non-SARS-CoV-2).

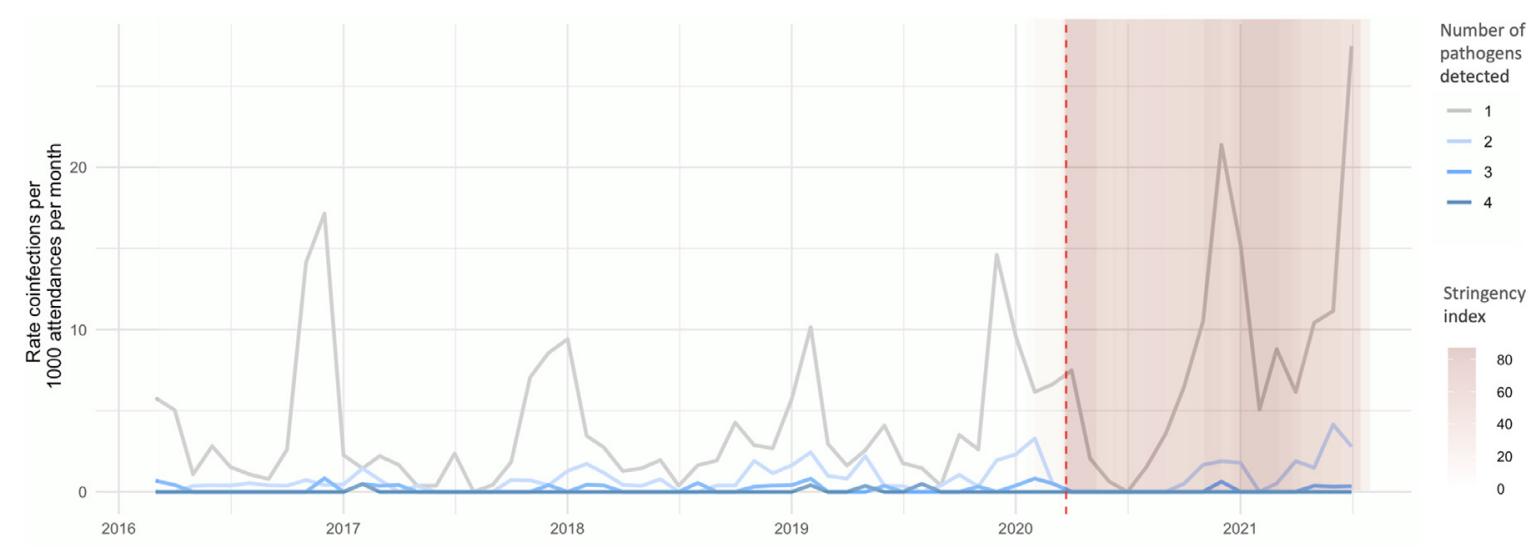

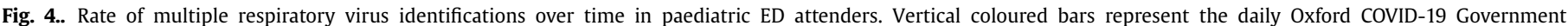

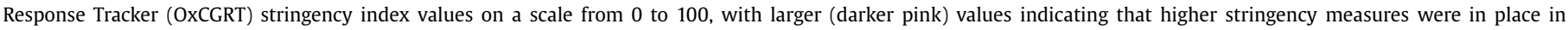
England. Red vertical dotted line indicates start of pandemic period, defined here as March 2020.

more than one (134 with two pathogens, 27 with three pathogens and 4 with four pathogens). There were no samples positive for $>1$ pathogen during the first national lockdown. Samples positive for $>1$ pathogen, potentially representing either active coinfection, or several infections arising over a short time period, took longer ( 2 months) to re-emerge after the relaxation of restrictions than samples with one pathogen. No samples positive for four pathogens were observed during the pandemic (Fig. 4).

\section{Disease severity}

Partial PEWS were calculated for 571 attendances with positive respiratory virus PCRs. There were no significant differences in PEWS between attendees diagnosed with different respiratory viral pathogens pre-pandemic ( $p=0.27$, Kruskal-Wallis). There was no significant difference between PEWS pre- and during the pandemic ( $p=0.24$, Mann-Witney U test). A higher PEWS was seen for 


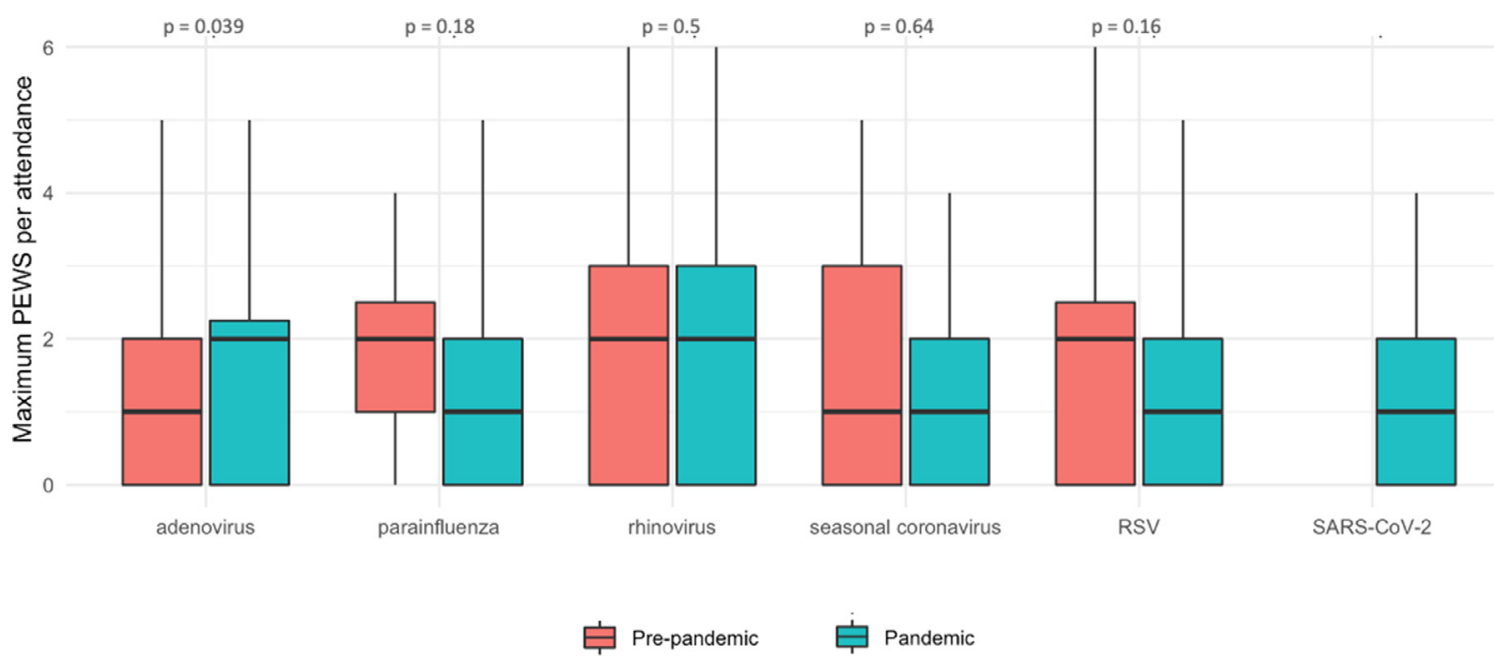

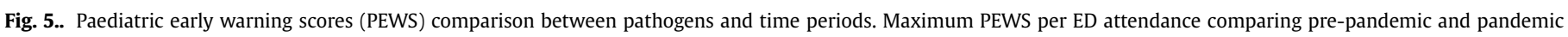

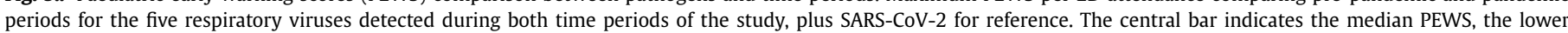

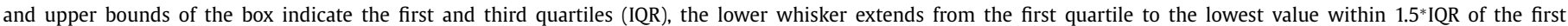

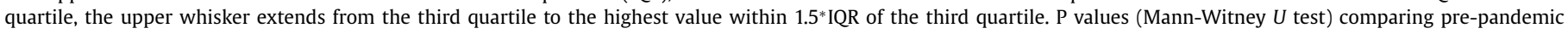
and pandemic PEWS for each pathogen are presented above the paired bars.

attendees with adenovirus during the pandemic compared to prepandemic ( $p=0.04$, Mann-Witney $U$ test), no other differences in PEWS between pre-pandemic vs. pandemic periods were seen for other pathogens (all p-values > 0.1, Mann-Witney $U$ test) (Fig. 5). There were fewer deaths within 14 days of a positive respiratory virus PCR during the pandemic than before the pandemic ( 0.3 vs. 0.8 deaths per 100 positive PCRs, respectively, $p<0.0001)$.

\section{Discussion}

Major changes in the incidence of paediatric viral RTI occurred in Oxfordshire during the pandemic, similarly to the rest of the UK. Following an initial period of low incidence for all pathogens during the first national lockdown, pathogen-dependent patterns of resurgence were seen from September 2020 onwards, with early resurgence of rhinovirus and adenovirus, and a delayed interseasonal resurgence of RSV. Although RSV detection rates in July 2021 were high, and occurred in older infants, cases were not clinically more severe.

Oxfordshire data pre-pandemic are representative of seasonal paediatric viral infections, with seasonal winter fluctuations of RSV and influenza, ${ }^{26}$ Seasonal winter patterns were eliminated during the first UK lockdown period and incidence remained low, as had been the case across Europe (with the exception of France and Iceland), ${ }^{27}$ until an inter-seasonal spike in RSV incidence in Oxfordshire in July 2021. Similar inter-seasonal RSV resurgences have been seen in the UK, Europe and countries in the Southern Hemisphere, ${ }^{9,15,21-23}$ also in older children, ${ }^{27,29-31}$ (likely due to lack of pre-existing immunity in 1-2 year olds due to decreased exposure) raising challenges for management of varying presentations of RSV in this older age group. It has been hypothesised that nursery and primary school closures have an impact on RSV transmission due to predominance in children under 5 years old; France and Iceland both had policies of keeping primary schools and daycare facilities open. ${ }^{27}$ In Oxfordshire, the inter-seasonal RSV spike occurred just as schools closed for the summer holidays, alongside presentations occurring predominantly in pre-school aged children, this raises the question whether daycare settings for younger children (which largely remain open over the summer) are the primary source of transmission, with case numbers fuelled by easing of lockdown measures within the general population, parents returning to work and easing of COVID restrictions in daycare settings.
This inter-seasonal RSV peak required a change of testing strategy with an introduction of out-of-season RSV testing and an extension of monthly preventative palivizumab for infants at risk for severe RSV disease, ${ }^{26,28}$ and contributed to an uncharacteristic summer peak in paediatric ED attendances and pressure on staffing. Influenza remained suppressed throughout, a pattern seen globally, ${ }^{32}$ presenting challenges for the selection of vaccine strains for the future winter influenza vaccination campaign.

In contrast, less seasonal variability was seen with rhinoviruses pre-pandemic; although their relative prevalence decreases in winter due to influenza interference, they are usually the most prevalent respiratory viral agent during summer months. ${ }^{33,34}$ Rhinovirus incidence increased to rates above those seen pre-pandemic in September-December 2020 (a period where schools and daycare were open and lockdown rules were relaxed), fell in JanuaryFebruary 2021, and rose again March-May 2021. Similar rhinovirus resurgences were seen in Australia, ${ }^{35}$ Germany, ${ }^{18}$ New Zealand, ${ }^{19}$ Japan ${ }^{20}$ and in adults in England. ${ }^{17}$ A rapid rise in adenovirus, similar to that seen for rhinoviruses after school re-opening, was seen in this study. HCoV show a winter seasonal pattern pre-pandemic, with a rise in detection in May-June 2021. Parainfluenza virus patterns were inconsistent pre-pandemic, rising in June 2021. SARSCoV-2 incidence reflects the national pandemic infection curves. Reassuringly, no increase in severity (measured by PEWS) was seen in the pandemic period, except for adenovirus.

Although it is clear that social distancing measures and school/daycare closures dramatically decreased the incidence of all respiratory viruses at the start of the pandemic, it is difficult to disaggregate the effect of social distancing in general vs. the specific impact of school closures thereafter. It is interesting to note that whilst rhinovirus and adenovirus cases tend to fluctuate with school openings, the rise in RSV cases in July 2021 occurred at the point when schools were closing for the summer holidays. Furthermore, the majority of cases in this study are in pre-school aged children, likely a combination of a true high incidence in this age group (as is usually the case) and a higher likelihood of severe illness in pre-school age children requiring hospital attendance. Therefore paradoxically, the greatest benefit of school closures and lockdown might be reducing community incidence of respiratory viruses and therefore acquisition and hospitalisation in the pre-school age group. An important piece of future work will be to understand which components of the public health 
interventions were most effective for preventing various respiratory virus infection and hospitalisation in different age groups, in particular understanding the contribution of school closures, given the many negative effects of closing schools on children and on society.

There are several hypotheses exploring the different patterns of resurgence between viral pathogens, including differences in the durability of immunity and the impact of reduced exposures on natural "boosting", respiratory virus "interference" in which one epidemic delays the start or accelerates the end of the other viral epidemic (as was seen in the 2009 influenza pandemic in which the RSV epidemic was also delayed), ${ }^{36-38}$ and differences in viral structure (for example the presence of an envelope) or transmission altering susceptibility to social distancing and inactivation by handwashing and surface cleaning.

There were limitations to this study. The retrospective nature of this study is subject to biases in data collection; respiratory diagnoses amongst ED attendees represent the more severe end of the disease spectrum and although these reflect community prevalence (this study shows similar trends to Public Health England surveillance data $^{39}$ ), they likely over-represent diagnoses in the pre-school children more likely to require hospital care for respiratory infection. Furthermore, some children, for example those with croup who are not conventionally sampled, are not represented in the dataset. Changes in healthcare seeking behaviours during the pandemic impact the calculated rates of infection, for example, families may have been deterred from attending hospital in person during the pandemic due to concerns about exposure to SARS-CoV-2. However this is partly mitigated by presenting respiratory diagnoses per 1000 attendances. The increased incidence of rhinovirus, adenovirus, hCoV and parainfluenza in the pandemic relative to pre-pandemic in this study is likely exaggerated by an ascertainment bias, due to increased use of the more comprehensive Biofire respiratory pathogen panel test for deteriorating patients or those requiring aerosol generating procedures during the pandemic and introduction of quadruple Influenza A/B/RSV/SARSCoV-2 admission screening in July 2021.

Although we have divided the study period into "pandemic" and "pre-pandemic" periods, SARS-CoV-2 circulated in the UK during the early weeks of 2020, defined here as "pre-pandemic". Since not all periods of lockdown are equivalent in terms of stringency, we used the Oxford COVID-19 government response tracker's Stringency Index ${ }^{24}$ to indicate the degree of restrictions in place throughout the study. However this stringency index does not capture population adherence to lockdown and social distancing measures.

Further studies, including the 'Bronchstart' study, ${ }^{40}$ will be required to assess the ongoing impact of the COVID-19 pandemic on respiratory virus incidence in both paediatric and adult populations, to inform workforce planning to adapt to changing seasonal patterns of service demand, altered testing strategies and use of anti-viral prophylaxis in high risk groups. We also need to understand which public health interventions are most effective for different pathogens, and assess whether any ongoing social distancing measures (for example public health messaging about hand washing, social distancing, ventilation and masking) could be useful to reduce the burden of RTI in the long term.

\section{Funding}

SFL is a Wellcome Trust Clinical Research Fellow. NES is an Oxford Martin Fellow and an NIHR Oxford BRC Senior Fellow. PCM holds a Wellcome Intermediate Fellowship $(110,110 / \mathrm{Z} / 15 / \mathrm{Z})$ and is an NIHR Oxford BRC Senior Fellow. DWE is a Robertson Foundation Fellow and an NIHR Oxford BRC Senior Fellow. ASW is an NIHR Senior Investigator. ASW and NS are supported by the NIHR Research
Health Protection Research Unit in Healthcare Associated Infections and Antimicrobial Resistance at the University of Oxford in partnership with Public Health England (PHE) (NIHR200915). ASW is supported by the NIHR Oxford Biomedical Research Centre. This study is funded/supported by the National Institute for Health Research (NIHR) Health Protection Research Unit in Healthcare Associated Infections and Antimicrobial Resistance (NIHR200915), a partnership between the UK Health Security Agency (UKHSA) and the University of Oxford, and the National Institute for Health Research (NIHR) Oxford Biomedical Research Centre (BRC). The views expressed are those of the author(s) and not necessarily those of the NHS, the NIHR, UKHSA or the Department of Health and Social Care. This research was funded in whole, or in part, by the Wellcome Trust [grant ref $110110 / Z / 15 / Z$ to PCM]. For the purpose of Open Access, the author has applied a CC BY public copyright licence to any Author Accepted Manuscript version arising from this submission.

\section{Declaration of Competing Interest}

DWE declares lecture fees from Gilead, outside the submitted work. No other author has a conflict of interest to declare.

\section{Acknowledgment}

We thank all the people of Oxfordshire who contribute to the Infections in Oxfordshire Research Database. Research Database Team: L Butcher, H Boseley, C Crichton, DW Crook, DW Eyre, O Freeman, J Gearing (community), R Harrington, K Jeffery, M Landray, A Pal, TEA Peto, TP Quan, J Robinson (community), J Sellors, B Shine, AS Walker, D Waller. Patient and Public Panel: G Blower, C Mancey, P McLoughlin, B Nichols

\section{Supplementary materials}

Supplementary material associated with this article can be found, in the online version, at doi:10.1016/j.jinf.2021.10.022.

\section{References}

1. GBD 2015 LRI Collaborators Estimates of the global, regional, and national morbidity, mortality, and aetiologies of lower respiratory tract infections in 195 countries: a systematic analysis for the global burden of disease study 2015. Lancet Infect Dis 2017;17(11):1133-61 Nov.

2. Jin X, Ren J, Li R, Gao Y, Zhang H, Li J, et al. Global burden of upper respiratory infections in 204 countries and territories, from 1990 to 2019. EClinicalMedicine 2021;37:100986 Jul.

3. Couriel J. Assessment of the child with recurrent chest infections. Br Med Bull 2002;61:115-32

4. Flood J, Shingleton J, Bennett E, Walker B, Amin-Chowdhury Z, Oligbu G, et al. Paediatric multisystem inflammatory syndrome temporally associated with SARS-CoV-2 (PIMS-TS): prospective, national surveillance, United Kingdom and Ireland, 2020. Lancet Reg Health Eur 2021;3:100075 Apr.

5. Shulman ST. Pediatric coronavirus disease-2019-Associated multisystem inflammatory syndrome. J Pediatric Infect Dis Soc 2020;9(3):285-6 Jul 13.

6. Whittaker E, Bamford A, Kenny J, Kaforou M, Jones CE, Shah P, et al. Clinical characteristics of 58 children with a pediatric inflammatory multisystem syndrome temporally associated with SARS-CoV-2. JAMA 2020;324(3):259-69 Jul 21.

7. Abo YN, Clifford V, Lee LY, Costa AM, Crawford N, Wurzel D, et al. COVID-19 public health measures and respiratory viruses in children in Melbourne. J Paediatr Child Health 2021 [Internet]Jun 3. doi:10.1111/jpc.15601.

8. Eyre TA, Peters L, Andersson MI, Peniket A, Eyre DW. Reduction in incidence of non-COVID-19 respiratory virus infection amongst haematology inpatients following UK social distancing measures. Br J Haematol 2021;195(2):194-7 [Internet]Oct.

9. Britton PN, Hu N, Saravanos G, Shrapnel J, Davis J, Snelling T, et al. COVID-19 public health measures and respiratory syncytial virus. Lancet Child Adolesc Health 2020:4(11):e42-3 Nov.

10. Kuitunen I, Artama M, Mäkelä L, Backman K, Heiskanen-Kosma T, Renko M. Effect of social distancing due to the COVID-19 pandemic on the incidence of viral respiratory tract infections in children in Finland during early 2020. Pediatr Infect Dis J 2020;39(12):e423-7 Dec. 
11. Calderaro A, De Conto F, Buttrini M, Piccolo G, Montecchini S, Maccari C, et al. Human respiratory viruses, including SARS-CoV-2, circulating in the winter season 2019-2020 in Parma, Northern Italy. Int J Infect Dis 2021;102:79-84 Jan.

12. Sherman AC, Babiker A, Sieben AJ, Pyden A, Steinberg J, Kraft CS, et al. The effect of severe acute respiratory syndrome coronavirus 2 (SARS-CoV-2) Mitigation strategies on seasonal respiratory viruses: a tale of 2 large metropolitan centres in the United States. Clin Infect Dis 2021;72(5):e154-7.

13. Nolen LD, Seeman S, Bruden D, Klejka J, Desnoyers C, Tiesinga J, et al. Impact of social distancing and travel restrictions on non-coronavirus disease 2019 (NonCOVID-19) respiratory hospital admissions in young children in rural Alaska. Clin Infect Dis 2021;72(12):2196-8 Jun 15 .

14. Redlberger-Fritz M, Kundi M, Aberle SW, Puchhammer-Stöckl E. Significant impact of nationwide SARS-CoV-2 lockdown measures on the circulation of other respiratory virus infections in Austria. J Clin Virol 2021;137:104795 Apr.

15. Olsen SJ, Winn AK, Budd AP, Prill MM, Steel J, Midgley CM, et al. Changes in influenza and other respiratory virus activity during the COVID-19 pandemic United States, 2020-2021. MMWR Morb Mortal Wkly Rep 2021;70(29):1013-19 Jul 23.

16. Park S, Michelow IC, Choe YJ. Shifting patterns of respiratory virus activity following social distancing measures for COVID-19 in South Korea. J Infect Dis 2021:jiab231 [Internet]May 1.

17. Poole S, Brendish NJ, Tanner AR, Clark TW. Physical distancing in schools for SARS-CoV-2 and the resurgence of rhinovirus. Lancet Respir Med 2020;8(12):e92-3 Dec.

18. Oh DY, Buda S, Biere B, Reiche J, Schlosser F, Duwe S, et al. Trends in respiratory virus circulation following COVID-19-targeted nonpharmaceutical interventions in Germany, January-September 2020: analysis of national surveillance data. Lancet Reg Health Eur 2021;6:100112 Jul.

19. Huang QS, Wood T, Jelley L, Jennings T, Jefferies S, Daniells K, et al. Impact of the COVID-19 nonpharmaceutical interventions on influenza and other respiratory viral infections in New Zealand. Nat Commun 2021;12(1):1001 Feb 12.

20. Takashita E, Kawakami C, Momoki T, Saikusa M, Shimizu K, Ozawa H, et al. Increased risk of rhinovirus infection in children during the coronavirus disease-19 pandemic. Influenza Other Respir Viruses 2021;15(4):488-94 Jul.

21. National Center for Immunization and Respiratory Diseases (NCIRD), Division of Viral Diseases, RSV National Trends [Internet]. 2021 [cited 2021 Aug 4]. Available from: https://www.cdc.gov/surveillance/nrevss/rsv/natl-trend.html

22. Agha R, Avner JR. Delayed seasonal RSV surge observed during the COVID-19 pandemic. Pediatrics 2021;148(3):e2021052089 [Internet]Sep.

23. Foley DA, Yeoh DK, Minney-Smith CA, Martin AC, Mace AO, Sikazwe CT, et al. The interseasonal resurgence of respiratory syncytial virus in Australian children following the reduction of coronavirus disease 2019-related public health measures. Clin Infect Dis 2021:ciaa1906 [Internet]Feb 17.

24. Hale T, Angrist N, Goldszmidt R, Kira B, Petherick A, Phillips T, et al. A global panel database of pandemic policies (Oxford COVID-19 government response tracker). Nat Hum Behav 2021;5(4):529-38 Apr.

25. Sefton G, Lane S, Killen R, Black S, Lyon M, Ampah P, et al. Accuracy and efficiency of recording pediatric early warning scores using an electronic physiological surveillance system compared with traditional paper-based documentation. Comput Inform Nurs 2017;35(5):228-36 May.

26. UK Health Security Agency, Respiratory Syncytial Virus -Green Book Chapter 27a [Internet]. cited 2021 Sep 14. Available from: https://assets.publishing. service.gov.uk/government/uploads/system/uploads/attachment_data/file/ 458469/Green_Book_Chapter_27a_v2_0W.PDF
27. van Summeren J, Meijer A, Aspelund G, Casalegno JS, Erna G, Hoang U, et al. Low levels of respiratory syncytial virus activity in Europe during the 2020/21 season: what can we expect in the coming summer and autumn/winter? Eurosurveillance 2021;26(29):2100639 [Internet]Jul.

28. Department of Health and Social Care, COVID-19 Therapeutic Alert Palivizumab passive immunisation against respiratory syncytial virus (RSV) in at risk pre-term infants, CAS-ViewAlert [Internet]. [cited 2021 Sep 14]. Available from: https://www.cas.mhra.gov.uk/ViewandAcknowledgment/ViewAlert. aspx?AlertID=103163

29. Foley DA, Phuong LK, Peplinski J, Lim SM, Lee WH, Farhat A, et al. Examining the interseasonal resurgence of respiratory syncytial virus in Western Australia. Arch Dis Child 2021 [Internet]Aug 25archdischild-2021-322507.

30. Yeoh DK, Foley DA, Minney-Smith CA, Martin AC, Mace AO, Sikazwe CT, et al. Impact of coronavirus disease 2019 public health measures on detections of influenza and respiratory syncytial virus in children during the 2020 Australian winter. Clin Infect Dis 2021;72(12):2199-202 Jun 15.

31. McNab S, Ha Do LA, Clifford V, Crawford NW, Daley A, Mulholland K, et al. Changing epidemiology of respiratory syncytial virus in Australia - DELAYED re-emergence in Victoria compared to WA/NSW after prolonged lockdown for COVID-19. Clin Infect Dis 2021:ciab240 [Internet]Mar 18.

32. World Health Organisation. Global influenza programme - update $\mathrm{N}^{\circ} 400$ [Internet]. [cited 2021 Aug 31]. Available from: https://www.who.int/teams/ global-influenza-programme/surveillance-and-monitoring/influenza-updates/ current-influenza-update

33. Kloepfer KM, Gern JE. Ecological and individual data both indicate that influenza inhibits rhinovirus infection. Proc Natl Acad Sci U S A 2020;117(13):6987 Mar 31.

34. Nickbakhsh S, Mair C, Matthews L, Reeve R, Johnson PCD, Thorburn F, et al. Virus-virus interactions impact the population dynamics of influenza and the common cold. Proc Natl Acad Sci U S A 2019 [Internet]Dec 16Available from. doi:10.1073/pnas.1911083116.

35. Marriott D, Beresford R, Mirdad F, Stark D, Glanville A, Chapman S, et al. Concomitant marked decline in prevalence of severe acute respiratory syndrome coronavirus 2 (SARS-CoV-2) and other respiratory viruses amongst symptomatic patients following public health interventions in Australia: data from St Vincent's hospital and associated screening clinics, Sydney, NSW. Clin Infect Dis 2021;72(10):e649-51 May 18.

36. Chan KF, Carolan LA, Korenkov D, Druce J, McCaw J, Reading PC, et al. Investigating viral interference between influenza a virus and human respiratory syncytial virus in a ferret model of infection. J Infect Dis 2018;218(3):406-17 Jul 2.

37. Li Y, Wang X, Msosa T, de Wit F, Murdock J, Nair H. The impact of the 2009 influenza pandemic on the seasonality of human respiratory syncytial virus: a systematic analysis. Influenza Other Respir Viruses 2012;6(3):e6-10 [Internet]May.

38. Anestad G. Interference between outbreaks of respiratory syncytial virus and influenza virus infection. Lancet 1982;319:502.

39. Public Health England. Weekly national influenza and COVID-19 report: week 34 report [Internet]. [cited 2021 Aug 31]. Available from: https://assets.publishing.service.gov.uk/government/uploads/system/uploads/ attachment_data/file/1013593/Weekly_Flu_and_COVID-19_report_w34.pdf

40. Williams TC, Lyttle MD, Cunningham S, Sinha I, Swann OV, Maxwell-Hodkinson A, et al. Study pre-protocol for "BronchStart - the impact of the COVID-19 pandemic on the timing, age and severity of respiratory syncytial virus (RSV) emergency presentations; a multi-centre prospective observational cohort study.". Wellcome Open Res 2021;6:120 May 19. 